\title{
Causal effects of motor control on gait kinematics after orthopedic surgery in cerebral palsy: a machine-learning approach
}

\author{
Katherine M. Steele ${ }^{1}$, Michael H. Schwartz ${ }^{2,3}$ \\ 1 University of Washington \\ 2 Gillette Children's Specialty Healthcare \\ 3 University of Minnesota, Department of Orthopedic Surgery
}

\begin{abstract}
Background: Altered motor control is common in cerebral palsy (CP). Understanding how altered motor control effects movement and treatment outcomes is important, but challenging due to complex interactions between impairments. While regression can be used to examine associations between impairments and gait, causal modeling provides a mathematical framework to specify assumed causal relationships, identify covariates that may introduce bias, and test model plausibility. The goal of this research was to quantify the causal effects of altered motor control and other impairments on gait, before and after single-event multi-level orthopedic surgery (SEMLS).
\end{abstract}

Methods: We evaluated the impact of SEMLS on change in Gait Deviation Index ( $\Delta$ GDI) between gait analyses. We constructed our causal model with a Directed Acyclic Graph that included the assumed causal relationships between SEMLS, $\triangle$ GDI, baseline GDI (GDI pre), baseline neurologic and orthopedic impairments ( $\operatorname{Imp}_{\text {pre }}$ ), age, and surgical history. We identified the adjustment set to evaluate the causal effect of SEMLS on $\triangle$ GDI and the impact

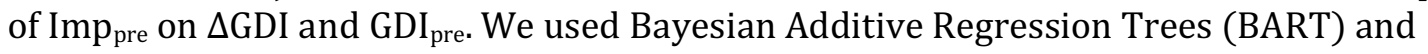
accumulated local effects to assess relative effects.

Results: We prospectively recruited a cohort of children with bilateral CP undergoing SEMLS (N=54, 35 males, age: $10.5 \pm 3.1$ years) and identified a control cohort with bilateral CP who did not undergo SEMLS ( $\mathrm{N}=55,30$ males, age: 10.0 \pm 3.4 years). There was a small positive causal effect of SEMLS on $\triangle \mathrm{GDI}$ (1.68 GDI points). Altered motor control (i.e.,

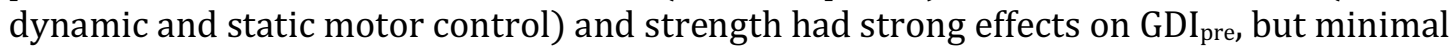
effects on $\Delta$ GDI. Spasticity and orthopedic impairments had minimal effects on GDI pre $_{\text {or }}$ $\Delta \mathrm{GDI}$.

Conclusions: Altered motor control and other baseline impairments did have a strong effect on $\mathrm{GDI}_{\text {pre, }}$ indicating that these impairments do have a causal effect on a child's gait pattern but minimal effect on expected changes in GDI after SEMLS. Heterogeneity in outcomes suggests there are other factors contributing to changes in gait. Identifying these factors and employing causal methods to examine the complex relationships between impairments and movement will be required to advance our understanding and care of children with CP. 
medRxiv preprint doi: https://doi.org/10.1101/2022.01.04.21268561; this version posted January 5, 2022. The copyright holder for this preprint (which was not certified by peer review) is the author/funder, who has granted medRxiv a license to display the preprint in perpetuity.

It is made available under a CC-BY-NC-ND 4.0 International license .

\section{Introduction}

Children diagnosed with cerebral palsy (CP) exhibit altered motor control due to an injury to the brain at or near the time of birth ${ }^{1-3}$. Altered motor control can be observed in CP in many ways, such as increased co-contraction, decreased capacity to selectively move individual joints, decreased complexity of control, and altered movement patterns. Prior research has suggested that quantifying motor control is important to understand function and inform treatment planning ${ }^{4-8}$. However, altered motor control occurs and interacts with many other impairments in $\mathrm{CP}$, which makes quantifying and isolating the effects of altered motor control challenging.

In addition to altered motor control, children with $\mathrm{CP}$ often have other neurologic impairments such as spasticity, dystonia, or muscle weakness. Over time, orthopedic impairments can also develop, including muscle contractures and altered bone morphology ${ }^{9-13}$. Together, these neurologic and orthopedic impairments contribute to limitations in movement, which reduce walking speed, elevate walking energy cost, and limit the capacity of children with CP to participate in daily activities ${ }^{14-18}$.

The complexity of CP makes it challenging to objectively determine the causal effects of specific impairments, such as altered motor control, on gait. As a result, many children with CP undergo clinical gait analysis (CGA) ${ }^{19}$, which provides quantitative measures of a child's gait pattern that can be tracked over time and used to inform treatment decisions ${ }^{20-22}$. In particular, CGA was historically developed to support decision making for orthopedic surgery ${ }^{23-26}$. Many children's hospitals now have CGA laboratories used for pre-operative and post-operative assessments.

While CGA has been used for treatment planning for over 30 years, deciphering causal effects of impairments on gait has remained elusive. Data from CGA is traditionally used to evaluate associations between a specific impairment and an outcome measure, typically using bivariate or multivariate regression analyses applied to retrospective data ${ }^{27-31}$. In cases where multivariate regression has been used, the choice of variables for inclusion has often not had a clear causal basis. Our prior work to evaluate the impact of motor control on 
gait and treatment outcomes have relied on these methods ${ }^{5,6,32}$. Using multivariate regression with retrospective data from multiple hospitals we have repeatedly demonstrated that Dynamic Motor Control (DMC) during walking is associated with function (i.e., Gross Motor Functional Classification System Levels or Gillette Functional Assessment Questionnaire) and outcomes (i.e., Gait Deviation Index, Walking Speed, Pediatric Outcomes Data Collection Instrument) after orthopedic surgery, rhizotomy, or botulinum toxin injections6,32. Similar analyses have demonstrated that other impairments such as strength, hamstring length, motor control, or torsional deformities - are also correlated with treatment outcomes ${ }^{33-37 .}$

Understanding whether altered motor control or other impairments cause altered gait or treatment outcomes is nearly impossible with non-causal regression alone. Given the complexity and heterogeneity of CP, this "implied cause by association" approach, without regard to possible confounding, is likely to lead to confusing and even erroneous conclusions. For example, researchers may observe that strength is associated with walking speed. However, strength is also affected by other primary neurologic deficits, like poor motor control, which may have an independent causal impact on speed. Understanding causal effects is impossible without considering these causal pathways and adjusting for relevant factors.

In recent years, there has remarkable growth in the development and successful applications of causal inference methods ${ }^{38,39}$. From a conceptual perspective, causal methods allow researchers to explicitly share assumed causal relationships and mathematically define covariates necessary for estimating causal effects ${ }^{40}$. From a computational perspective, numerous algorithms have been developed for modeling causal outcomes. Among the most successful of these are Bayesian Additive Regression Trees (BART), which have been shown to produce estimates of causal effects with low levels of bias and variance, and realistic confidence intervals ${ }^{41-44}$. Williams and colleagues (2018) have highlighted the potential of causal inference for pediatrics ${ }^{45}$. However, these methods have had limited application in CP or biomechanics research. 
medRxiv preprint doi: https://doi.org/10.1101/2022.01.04.21268561; this version posted January 5, 2022. The copyright holder for this preprint (which was not certified by peer review) is the author/funder, who has granted medRxiv a license to display the preprint in perpetuity.

It is made available under a CC-BY-NC-ND 4.0 International license .

The goal of this research was to quantify the causal effects of motor control and other impairments on gait, before and after orthopedic surgery. Specifically, we prospectively recruited children with $\mathrm{CP}$ who were undergoing single-event multilevel orthopedic surgery (SEMLS). We also identified a cohort of controls from the same time period who were not undergoing SEMLS between gait analyses. We developed a causal model and used BART to quantify the effects of motor control and other impairments on changes in gait kinematics after SEMLS. These methods provide a foundation for understanding the complex and interactive effects of impairments on gait for children with CP.

\section{Methods}

\subsection{Participants}

We recruited children with bilateral CP who were between 6 and 18 years old at the time of baseline gait analyses and scheduled for SEMLS. The goal of our prospective recruitment was to follow a representative cohort of patients at Gillette Children's Specialty Healthcare from their baseline gait analysis through two follow-up assessments at six-months and oneyear after SEMLS. The one-year analysis was our primary outcome; however, the COVID-19 pandemic interrupted the one-year follow-up for two participants, and we used the sixmonth follow-up visit for these participants. We included patients whose baseline gait analysis was no more than six months before their scheduled surgery date. We defined SEMLS as surgery consisting of two or more major orthopedic procedures on a single side. We also identified a cohort of controls with CP who did not undergo SEMLS. We identified children with bilateral CP who underwent multiple gait analyses with kinematic and electromyographic (EMG) recordings, with a maximum time of 2.5 years between visits during the same time period. We excluded participants who underwent prior or current rectus femoris transfer, since we were evaluating motor control from EMG recordings. This research was conducted with approval from the University of Minnesota Institutional Review Board. 
medRxiv preprint doi: https://doi.org/10.1101/2022.01.04.21268561; this version posted January 5, 2022. The copyright holder for this preprint (which was not certified by peer review) is the author/funder, who has granted medRxiv a license to display the preprint in perpetuity.

It is made available under a CC-BY-NC-ND 4.0 International license .

\subsection{Causal Model}

For this analysis we focused on evaluating the impact of SEMLS on gait kinematics. We $a$ priori specified our outcome measure as the Gait Deviation Index (GDI, ClinicalTrials.gov NCT02699554) as a common summary measure of walking kinematics that has been used extensively in prior studies to evaluate and predict treatment outcomes.

We constructed our causal model with a Directed Acyclic Graph (DAG) ${ }^{46-48}$. The logic behind our DAG is as follows (Figure 1):

1. Our objective was to determine the impact of SEMLS on change in GDI ( $\triangle \mathrm{GDI}$ ). Thus, SEMLS is our exposure and $\triangle \mathrm{GDI}$ is our outcome. SEMLS induces a change in impairments $(\Delta \operatorname{Imp})$ that causes the observed $\Delta \mathrm{GDI}$.

2. The covariates we identified as common causes of both SEMLS (i.e., variables that impact the choice to undergo SEMLS) and $\triangle \mathrm{GDI}$ included: Age, baseline GDI (GDI pre), and baseline impairment (Imp pre). Baseline impairments represent a set of variables collected during CGA to evaluate neurologic and orthopedic impairments (Table 1).

3. Surgical treatment history $(\mathrm{Hx})$ is a common cause of baseline impairment (Impre) and whether or not SEMLS is recommended.

4. We included a general severity (Sev) measure as an unmeasured factor that impacts baseline impairment ( $\left(\mathrm{Imp}_{\mathrm{pre}}\right)$ and surgical treatment history $(\mathrm{Hx})$.

Note that similar DAGs could be constructed for other outcome measures such as walking speed or energy cost. Similarly, additional factors could be added to the DAG, if there were rational arguments that they were common causes of one of the variables in the DAG and $\Delta G D I$. The step-by-step process we used to construct our DAG is illustrated in the Supplementary Material.

From the DAG we determined the variables that needed to be included in any model (e.g., regression, BART) to evaluate the total causal effect of SEMLS on $\triangle$ GDI. These variables are called the adjustment set, representing the confounding covariates that could produce bias if not included in an analysis. For this DAG, the minimal sufficient adjustment set to estimate

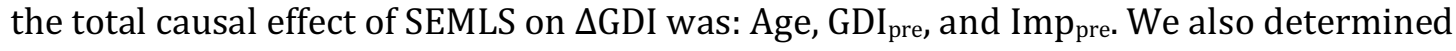


medRxiv preprint doi: https://doi.org/10.1101/2022.01.04.21268561; this version posted January 5, 2022. The copyright holder for this preprint (which was not certified by peer review) is the author/funder, who has granted medRxiv a license to display the preprint in perpetuity.

It is made available under a CC-BY-NC-ND 4.0 International license.

the adjustment set to evaluate the total causal effect of baseline impairment ( $\left.\operatorname{Imp}_{\text {pre }}\right)$ on

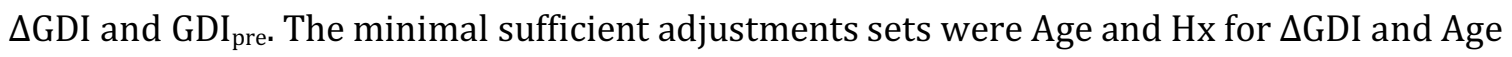

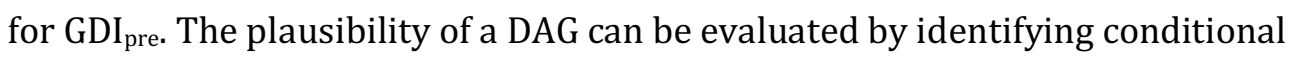
independencies, variables that should be independent given the causal relationships defined in the DAG. We identified the adjustment sets and independencies with dagitty 49 and all analyses were conducted in R (version 4.1.0) $)^{50}$.

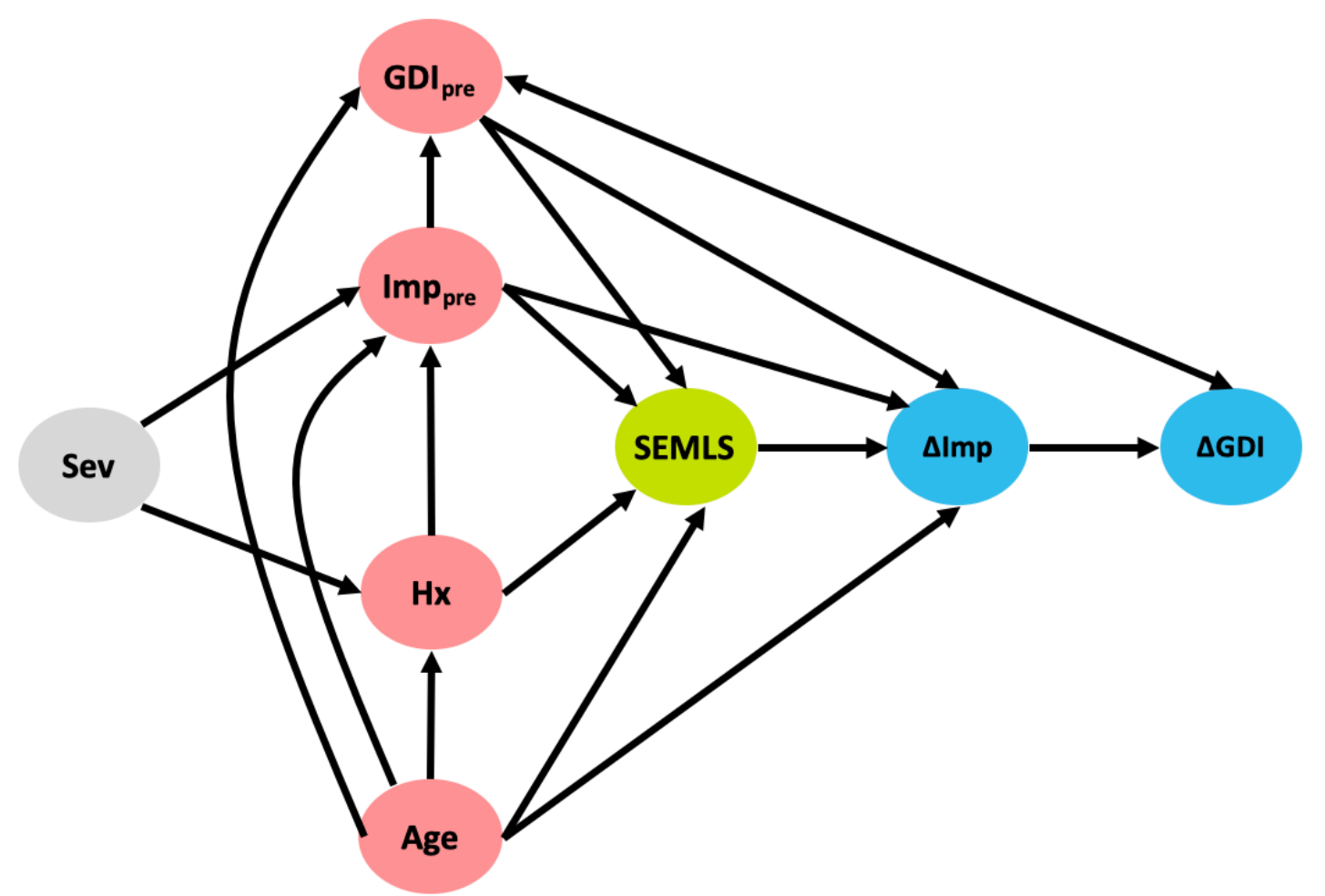

Figure 1: DAG describing the assumed causal relationships between SEMLS (exposure) and $\triangle G D I$ (outcome). The causal relationship between SEMLS and $\triangle G D I$ is mediated by changes in impairments ( $\triangle I m p)$. Baseline GDI

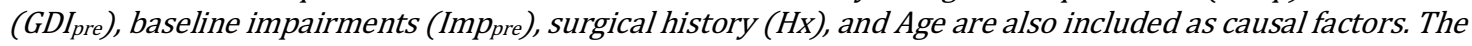
$D A G$ also includes unmeasured factors related to general CP severity, which impact baseline impairments and surgical history. The step-by-step process and rationale for this DAG are available in the Supplementary Material (http://dagitty.net/mUCSPWo). 
Table 1: Variable definitions

\begin{tabular}{|c|c|}
\hline Variable & Description \\
\hline GDI & $\begin{array}{l}\text { Overall measure of the deviation in an individual's kinematics compared to nondisabled } \\
\text { peers scaled such that mean(sd) over the nondisabled population is } 100(10)^{51} \text {. } \\
\text { Kinematics were evaluated using marker-based motion analysis and a modified plug-in- } \\
\text { gait marker set. }\end{array}$ \\
\hline SEMLS & $\begin{array}{l}\text { Binary variable indicating whether or not child had single-event multi-level orthopedic } \\
\text { surgery, defined as a surgery with two or more orthopedic surgeries on at least one leg. }\end{array}$ \\
\hline $\mathrm{Hx}$ & Binary list of prior surgical treatments. \\
\hline Age & Years from birth defined as days/365.25 \\
\hline \multirow{6}{*}{ 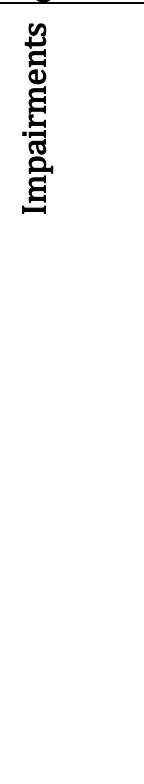 } & $\begin{array}{l}\text { Spasticity: Mean modified Ashworth score across plantarflexors, hamstrings, hip } \\
\text { adductors, and rectus femoris. }\end{array}$ \\
\hline & $\begin{array}{l}\text { Strength: Mean manual muscle strength score across hip flexors/extensors, knee } \\
\text { flexors/extensors, and ankle dorsiflexors/plantarflexors where } 1 \text { is defined as a 'visible } \\
\text { or palpable contraction' and } 5 \text { is defined as 'full range of motion against gravity'. }\end{array}$ \\
\hline & $\begin{array}{l}\text { Static Motor Control (SMC): Mean static motor control score across hip abduction, hip } \\
\text { flexion, hip extension, knee extension, and ankle plantarflexion where } 0 \text { is very little or } \\
\text { no control of single joint movement, } 1 \text { is impaired voluntary movement at a single joint, } \\
\text { and } 2 \text { is good voluntary movement at a joint. }\end{array}$ \\
\hline & $\begin{array}{l}\text { Dynamic Motor Control (DMC): Measure of the complexity of muscle activity during } \\
\text { gait evaluated from synergy analysis of EMG data. Complexity is evaluated as the total } \\
\text { variance accounted for by one synergy of EMG data during CGA and compared to } \\
\text { nondisabled peers scaled such that mean(sd) over the nondisabled population is } \\
100(10)^{5,52} \text {. }\end{array}$ \\
\hline & $\begin{array}{l}\text { Torsional Deformity: Femoral anteversion and tibial torsion (bimalleolar axis angle) } \\
\text { measured during physical exam. }\end{array}$ \\
\hline & $\begin{array}{l}\text { Contracture: Measures of joint range of motion from physical exam including maximum } \\
\text { ankle dorsiflexion with the knee extended, maximum knee extension, unilateral } \\
\text { popliteal angle, and maximum hip extension measured during the Thomas Test. }\end{array}$ \\
\hline
\end{tabular}

\subsection{Bayesian Additive Regression Trees}

To assess the total causal effects of SEMLS and baseline impairments (Impre) on change in GDI ( $\Delta \mathrm{GDI})$ we used Bayesian Additive Regression Trees (BART), a machine learning method that uses a boosted ensemble of regression trees for nonparametric function estimation relying on a Bayesian probability model ${ }^{41}$. Like other tree-based regression methods, an advantage of BART is that it can handle nonlinear effects and interactions ${ }^{53}$. For causal modeling, recent work has demonstrated that BART-based models achieve accurate and precise causal predictions $\mathrm{s}^{43,44}$.

For this analysis, we used BART models to estimate $\triangle$ GDI using the adjustment sets identified by the DAG. Thus, to identify the impact of SEMLS on $\triangle$ GDI, we included the covariates Age, GDI pre, and Imp pre. Baseline impairments were not available for all 
medRxiv preprint doi: https://doi.org/10.1101/2022.01.04.21268561; this version posted January 5, 2022. The copyright holder for this preprint (which was not certified by peer review) is the author/funder, who has granted medRxiv a license to display the preprint in perpetuity.

It is made available under a CC-BY-NC-ND 4.0 International license .

participants. Missing data in Imp pre were imputed using multivariate imputation by chained equations (MICE) ${ }^{54}$. We used the bartMachine package to implement the analysis ${ }^{55}$. We optimized the hyperparameters for each BART model using 10-fold cross-validation. We report the pseudo- $\mathrm{R}^{2}(1-S S E / S S T)$ for each BART model and used k-fold cross-validation $(k=10)$ to determine the out-of-sample root mean square error (RMSE).

To assess the relative effects of individual variables from BART, we used accumulated local effect (ALE) analysis ${ }^{56}$. The ALE analysis is similar to a partial dependence plot, but the averaging is done locally to avoid including observations that are unlikely to ever be realized (e.g., someone walking three standard deviations slower than average but with a normal cadence). The ALE plots illustrate the impact of each variable over the range of values for that variable, conditioned on the other covariates in the model. Thus, ALE plots can be useful for examining nonlinear effects identified by BART. For example, the ALE plot can highlight nonlinear effects such as when a variable impacts GDI with a deviation from average (i.e., a U-shaped plot) or when a variable only impacts GDI above or below a certain cut-off (i.e., a step function or discontinuity).

\section{Results}

\subsection{Participants}

We prospectively recruited 54 children with bilateral CP who underwent SEMLS (Table 2). During this same time period, we identified 55 children with bilateral CP who visited the gait laboratory for repeat visits and no intervening surgical procedures. The participants who underwent SEMLS were older and had more femoral anteversion, more tibial torsion, and lower GDI scores at the initial gait analysis than the patients who did not undergo SEMLS. The SEMLS participants received, on average, five procedures (Figure 2). 
medRxiv preprint doi: https://doi.org/10.1101/2022.01.04.21268561; this version posted January 5, 2022. The copyright holder for this preprint (which was not certified by peer review) is the author/funder, who has granted medRxiv a license to display the preprint in perpetuity.

It is made available under a CC-BY-NC-ND 4.0 International license.

Table 2: Participant characteristics, average (SD)

\begin{tabular}{|l|c|c|}
\hline & No SEMLS & SEMLS \\
\hline $\mathbf{N}$ & 55 & 54 \\
\hline Males N & 30 & 35 \\
\hline Age (years) & $10.0(3.4)$ & $10.5(3.1)$ \\
\hline GDI & $69.4(10.0)$ & $68.8(12.1)$ \\
\hline GDI Post & $69.2(11.9)$ & $71.4(11.7)$ \\
\hline SMC & $1.23(0.42)$ & $1.11(0.40)$ \\
\hline DMC & $81.1(9.0)$ & $80.6(9.6)$ \\
\hline Strength & $3.36(0.59)$ & $3.55(0.67)$ \\
\hline Spasticity & $1.16(0.42)$ & $1.30(0.46)$ \\
\hline Anteversion $\left(^{\circ}\right)$ & $36.3(10.4)$ & $39.6(11.3)$ \\
\hline Bimalleolar $\left(^{\circ}\right)$ & $12.6(10.6)$ & $13.4(11.4)$ \\
\hline Dorsiflexion $\left(^{\circ}\right)$ & $1.16(7.90)$ & $-0.52(7.48)$ \\
\hline Knee Extension $\left(^{\circ}\right)$ & $0.52(6.60)$ & $0.22(7.51)$ \\
\hline Thomas Test $\left(^{\circ}\right)$ & $0.61(6.23)$ & $2.25(6.16)$ \\
\hline Popliteal Angle $\left(^{\circ}\right)$ & $51.5(15.4)$ & $55.9(12.9)$ \\
\hline
\end{tabular}
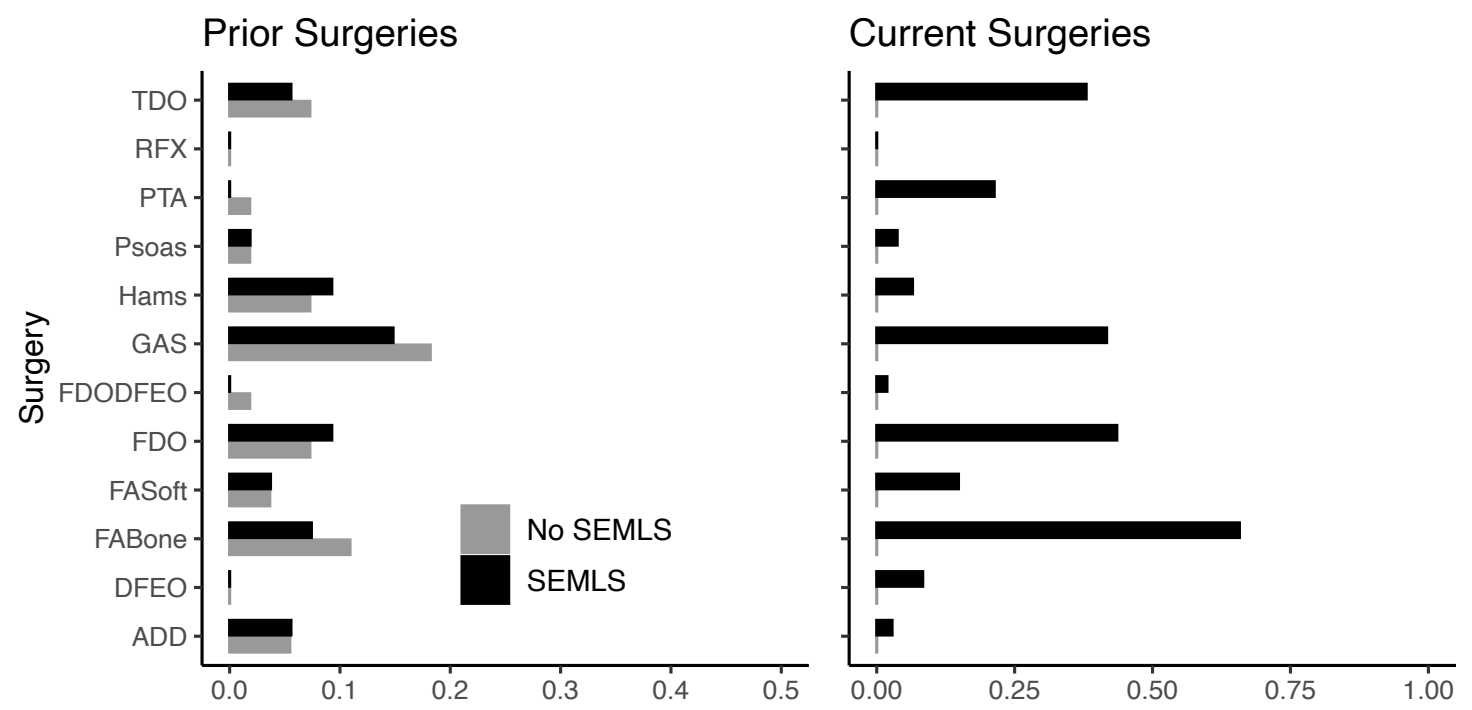

Figure 2: Prior and current surgeries of participants in both cohorts. Note that we excluded potential participants who underwent rectus femors transfer. TDO = tibial derotation osteotomy, $R F X=$ rectus femoris transfer, $P T A=$ patellar tendon advancement, Psoas $=$ psoas lengthening or release, Hams = hamstring lengthening, GAS = plantarflexor lengthening, FDODFEO = distal femoral derotation and extension osteotomy, $F D O=$ femoral derotation osteotomy, FAsoft $=$ foot/ankle soft tissue procedure, FABone = foot/ankle boney procedure, $D F E O=$ distal femoral extension osteotomy, $A D D=$ adductor lengthening or release. 
medRxiv preprint doi: https://doi.org/10.1101/2022.01.04.21268561; this version posted January 5, 2022. The copyright holder for this preprint (which was not certified by peer review) is the author/funder, who has granted medRxiv a license to display the preprint in perpetuity.

It is made available under a CC-BY-NC-ND 4.0 International license .

\subsection{Effects of SEMLS}

There was a small positive causal effect of SEMLS on $\triangle$ GDI. The estimated total causal effect of SEMLS on $\triangle$ GDI was 1.68 GDI points, representing the difference between the SEMLS (+0.85 GDI points) and control (-0.83 GDI points) cohorts. While the average change in GDI between visits was $2.64 \pm 8.12$ for the SEMLS cohort and $-0.26 \pm 7.44$ for the control cohort, the total causal effects represents the estimated effect of SEMLS after adjusting for differences in Age, $\mathrm{GDI}_{\text {pre, }}$ and Imp pre. The BART model explained $18 \%$ of the variance in $\Delta \mathrm{GDI}$, with an out-of-sample root mean square error of 7.72. The implied conditional independencies of the DAG were also evaluated and all partial correlations were less than 0.20, supporting model plausibility (Supplementary Material).

\subsection{Effects of Impairments}

Baseline values of neurologic and orthopedic impairments (Imp pre) had minimal effects on

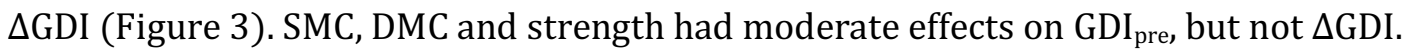
Greater SMC or DMC resulted in higher GDI $_{\text {pre }}$ Scores, while muscle weakness had a negative

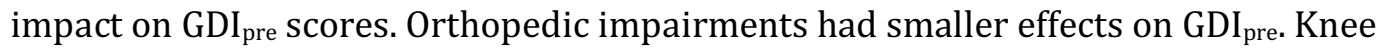
extension range of motion and tibial torsion (i.e., bimalleolar angle) had the largest effect among orthopedic impairments on GDI. Participants who had excessive knee range of motion (i.e., hyperextension) had worse baseline GDI scores. Contracture of the plantarflexors, hamstrings, or iliopsoas, as well as femoral anteversion had minimal impact on $\mathrm{GDI}_{\text {pre }}$ or $\Delta \mathrm{GDI}$. The BART models evaluating the effects of impairments explained $61 \%$ of the variance in $\mathrm{GDI}_{\text {pre }}$ and $9 \%$ of the variance in $\Delta \mathrm{GDI}$. Out-of-sample performance of the BART models were able to RMSE $=9.02$ for $\mathrm{GDI}_{\text {pre }}$ and RMSE $=7.97$ for $\Delta$ GDI. 


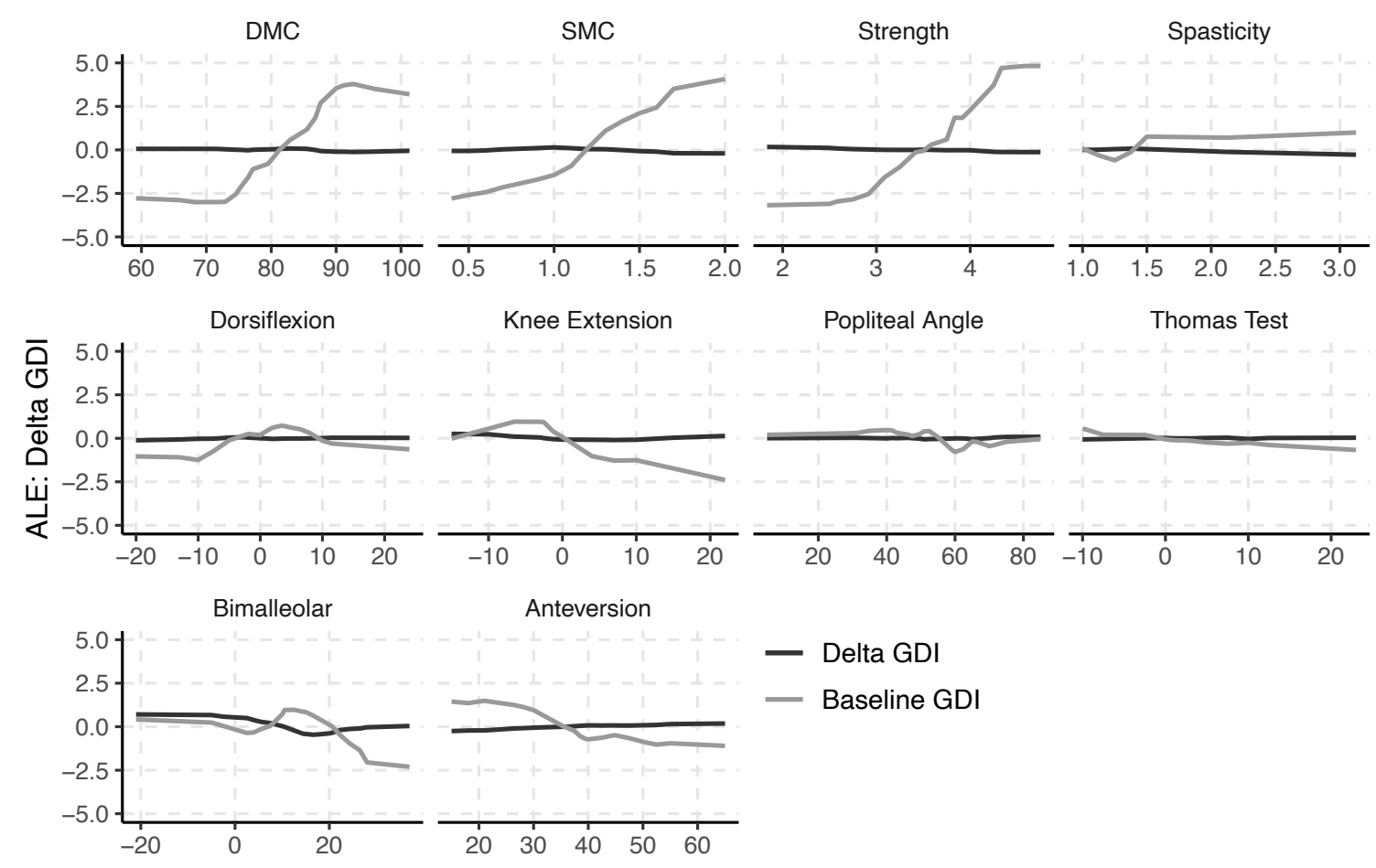

Figure 3: Accumulated local effects (ALE) of baseline neurologic and orthopedic impairments on GDIpre and $\triangle G D I$.

\section{Discussion}

This study showed that SEMLS has a small positive causal effect on change in GDI for children with bilateral CP. A ten-point change in GDI is generally considered a clinically significant improvement in walking function ${ }^{57}$. The observed change in GDI and total causal effect were far below this threshold. However, the cohorts who did not undergo SEMLS experienced a reduction in GDI between visits, resulting in a net effect of SEMLS around 1.68 GDI points. While average changes in GDI were modest, there was significant variation in outcome between participants, which could not be predicted by the model including baseline age, impairment level, or surgical history. We found that SEMLS produced an increase in GDI larger than five points for 35\% of participants, but also a decrease of more than five points in $20 \%$ of the participants. Such heterogeneous responses to SEMLS have motivated our team's investigations into patient-specific factors that can improve outcomes 
for children with CP. We ultimately want to be able to determine why an individual walks the way they do and anticipate their responses to treatment. We had previously hypothesized that motor control could be once such factor.

Our prior retrospective regression analyses demonstrated that DMC was associated with GDI after treatment across analyses at multiple clinical centers 5,6 . However, using a causal model to control for and evaluate the relative effects of various impairments indicated that motor control and other impairments had minimal causal effects on change in GDI. Importantly, DMC and other impairments had a strong effect on baseline GDI, indicating that these impairments do have a causal effect on a child's gait pattern. However, these impairments had minimal effect on $\triangle$ GDI. In other words, a child who has greater DMC at baseline was likely to have a higher GDI than a child with lower DMC, but better motor control had minimal effect on expected changes in GDI. An important point in these analyses is that the overall causal effect of SEMLS was small, which contributes to the small observed effects of impairments on $\Delta$ GDI. Despite these small treatment effects, the wide heterogeneity in outcomes suggests that there are still causal factors contributing to treatment outcome that we are missing. These may include post-operative rehabilitation, surgeon skill, or other measures of neurologic impairment. Identifying patient-specific factors that can help us understand the causal pathways that impact gait and treatment outcomes continues to be an important area for future research.

Causal modeling provides a framework to evaluate the complex relationships between impairments and outcomes in CP. We created a DAG to identify the assumed relationships between SEMLS and GDI. The DAG used in this research could be expanded to include more detail about the assumed causal relationships between specific neurologic and orthopedic impairments or to evaluate other outcome measures. Similarly, our goal in this research was not to make outcome predictions for individual patients. Rather, we wanted to understand the impact of SEMLS and impairments on GDI. This led us towards more coarse modeling choices. As an example, we ignored details of surgical procedures and did not attempt to define the causal relationships between various neurologic and orthopedic impairments, although this is an area for future study. 
The DAG we created for this research gave rise to the adjustment sets necessary to evaluate the impact of SEMLS and impairments on GDI. These adjustment sets can be used with any modeling method, including linear regression or other machine learning methods. We selected BART rather than linear regression or other models because we do not expect the impact of many impairments on gait to be linear. For example, we expect impairments like tibial torsion to reduce GDI scores with excessive internal or external rotation, producing a "u-shaped" response. Similarly, for some impairments like spasticity, there may be a threshold above or below which the impairment has an effect on gait. BART also provides a Bayesian framework that gives posterior distributions for each parameter.

A limitation in this research was that we did not recruit a prospective control group. Rather, we identified participants who were evaluated at multiple CGAs without any intervening surgical procedures. This cohort may also be subject to sample bias, but randomization is not feasible for this population. Since we were interested in evaluating DMC measured from EMG recordings, we also excluded children who underwent rectus femoris transfer, since the impact of moving the insertion of this muscle on recruitment and synergies remains unclear. Thus, this sample may not capture the impact of impairments that influence stiffknee gait in children with CP.

\subsection{Conclusions}

The overall causal effect of SEMLS on change in GDI is modest. While motor control and strength do influence an individual's gait pattern, their effect on expected changes in GDI after SEMLS are small. It is important to consider causal frameworks when analyzing observational data to avoid bias arising from confounding. Critically evaluating current CGA practices and integrating measures such as postoperative care, surgical details, or neuroimaging into treatment planning may enhance our ability to perform casual analyses aimed at understanding and improving movement for children with CP. 


\section{References}

1. Desloovere K. Pathophysiology, measurement, and treatment of spasticity in children. Neuromodulation. 2005 Jul;8(3):187-9.

2. Handsfield GG, Meyer CH, Abel MF, Blemker SS. Heterogeneity of muscle sizes in the lower limbs of children with cerebral palsy. Muscle Nerve. Wiley Online Library; 2016;53(6):933-945.

3. O'Brien SM, Carroll TJ, Barber LA, Lichtwark GA. Plantar flexor voluntary activation capacity, strength and function in cerebral palsy. Eur J Appl Physiol [Internet]. 2021 Mar 9 [cited 2021 Apr 6]; Available from: http://link.springer.com/10.1007/s00421021-04638-z

4. Fowler EG, Staudt LA, Greenberg MB. Lower-extremity selective voluntary motor control in patients with spastic cerebral palsy: increased distal motor impairment. Dev Med Child Neurol. 2010;52(3):264-269.

5. Shuman BR, Goudriaan M, Desloovere K, Schwartz MH, Steele KM. Associations Between Muscle Synergies and Treatment Outcomes in Cerebral Palsy Are Robust Across Clinical Centers. Arch Phys Med Rehabil. 2018;99(11):2175-2182. PMCID: PMC6179956

6. Schwartz MH, Rozumalski A, Steele KM. Dynamic motor control is associated with treatment outcomes for children with cerebral palsy. Dev Med Child Neurol. 2016 Nov;58(11):1139-1145. PMID: 27097830

7. Bekius A, Bach MM, van der Krogt MM, de Vries R, Buizer AI, Dominici N. Muscle Synergies During Walking in Children With Cerebral Palsy: A Systematic Review. Front Physiol. 2020 Jul 2;11:632.

8. Cahill-Rowley K, Rose J. Etiology of impaired selective motor control: emerging evidence and its implications for research and treatment in cerebral palsy. Dev Med Child Neurol. 2014;56(6):522-528.

9. Crane L. Femoral torsion and its relation to toeing-in and toeing-out. JBJS. 1959;41(3):421-428.

10. Lee SH, Chung CY, Park MS, Choi IH, Cho T-J. Tibial Torsion in Cerebral Palsy: Validity and Reliability of Measurement. Clin Orthop Relat Res. 2009 Aug 1;467(8):2098-2104.

11. Fabry G, MACEWEN GD, Shands Jr A. Torsion of the Femur: A follow-up study in normal and abnormal conditions. JBJS. 1973;55(8):1726-1738.

12. Mathewson MA, Lieber RL. Pathophysiology of muscle contractures in cerebral palsy. Phys Med Rehabil Clin. 2015;26(1):57-67. 
medRxiv preprint doi: https://doi.org/10.1101/2022.01.04.21268561; this version posted January 5, 2022. The copyright holder for this preprint (which was not certified by peer review) is the author/funder, who has granted medRxiv a license to display the preprint in perpetuity.

It is made available under a CC-BY-NC-ND 4.0 International license .

13. O'Dwyer NJ, Neilson PD, Nash J. Mechanisms of muscle growth related to muscle contracture in cerebral palsy. Dev Med Child Neurol. 1989 Aug;31(4):543-7.

14. Rose J, Gamble JG, Medeiros J, Burgos A, Haskell WL. Energy cost of walking in normal children and in those with cerebral palsy: comparison of heart rate and oxygen uptake. J Pediatr Orthop. 1989/05/01 ed. 1989 May;9(3):276-9.

15. Johnston TE, Moore SE, Quinn LT, Smith BT. Energy cost of walking in children with cerebral palsy: relation to the Gross Motor Function Classification System. Dev Med Child Neurol. 2004;46(01):34-38.

16. Kamp F, Lennon N, Holmes L, Dallmeijer A, Henley J, Miller F. Energy cost of walking in children with spastic cerebral palsy: relationship with age, body composition and mobility capacity. Gait Posture. 2014;40(1):209-214.

17. Bjornson KF, Zhou C, Stevenson RD, Christakis D. Relation of stride activity and participation in mobility-based life habits among children with cerebral palsy. Arch Phys Med Rehabil. 2014;95(2):360-368.

18. Gross PH, Bailes AF, Horn SD, Hurvitz EA, Kean J, Shusterman M, network cerebral palsy research. Setting a patient-centered research agenda for cerebral palsy: a participatory action research initiative. Dev Med Child Neurol. 2018;60(12):12781284.

19. Gage JR, Schwartz MH, Koop SE, Novacheck TF. The identification and treatment of gait problems in cerebral palsy. John Wiley \& Sons; 2009.

20. Gough M, Shortland AP. Can clinical gait analysis guide the management of ambulant children with bilateral spastic cerebral palsy? J Pediatr Orthop. 2008/11/27 ed. 2008 Dec;28(8):879-83.

21. Steinwender G, Saraph V, Scheiber S, Zwick EB, Uitz C, Hackl K. Intrasubject repeatability of gait analysis data in normal and spastic children. Clin Biomech. 2000 Feb 1;15(2):134-139.

22. Miller F, Castagno P, Richards J, Lennon N, Quigley E, Niiler T. Reliability of kinematics during clinical gait analysis: a comparison between normal and children with cerebral palsy. Gait Posture. 1996;4(2):169-170.

23. Gage JR, Fabian D, Hicks R, Tashman S. Pre- and postoperative gait analysis in patients with spastic diplegia: a preliminary report. J Pediatr Orthop. 1984/11/01 ed. 1984 Nov;4(6):715-25.

24. Gage JR, Novacheck TF. An update on the treatment of gait problems in cerebral palsy. J Pediatr Orthop B. 2001/12/01 ed. 2001 Oct;10(4):265-74. 
medRxiv preprint doi: https://doi.org/10.1101/2022.01.04.21268561; this version posted January 5, 2022. The copyright holder for this preprint (which was not certified by peer review) is the author/funder, who has granted medRxiv a license to display the preprint in perpetuity.

It is made available under a CC-BY-NC-ND 4.0 International license .

25. Sullivan K, Richards J, Miller F, Castagno P, Lennon N. Predicting the outcome of surgery for children with cerebral palsy using pre-operative gait analysis. Gait Posture. 1995;2(3):92.

26. Lee EH, Goh JC, Bose K. Value of gait analysis in the assessment of surgery in cerebral palsy. Arch Phys Med Rehabil. Elsevier; 1992;73(7):642-646.

27. MacWilliams BA, Prasad S, Shuckra AL, Schwartz MH. Causal factors affecting gross motor function in children diagnosed with cerebral palsy. medRxiv. Cold Spring Harbor Laboratory Press; 2020 Oct 28;2020.10.26.20217232.

28. Kramer JF, Ann MacPhail HE. Relationships Among Measures of Walking Efficiency, Gross Motor Ability, and Isokinetic Strength In Adolescents With Cerebral Palsy. Pediatr Phys Ther. 1994 Spring;6(1):3-9.

29. Damiano DL, Martellotta TL, Sullivan DJ, Granata KP, Abel MF. Muscle force production and functional performance in spastic cerebral palsy: relationship of cocontraction. Arch Phys Med Rhabilitation. 2000;81(7):895-900.

30. Shin H-I, Sung KH, Chung CY, Lee KM, Lee SY, Lee IH, Park MS. Relationships between Isometric Muscle Strength, Gait Parameters, and Gross Motor Function Measure in Patients with Cerebral Palsy. Yonsei Med J. Yonsei University College of Medicine; 2015 Nov 30;57(1):217-224.

31. Ross SA, Engsberg JR. Relationships Between Spasticity, Strength, Gait, and the GMFM66 in Persons With Spastic Diplegia Cerebral Palsy. Arch Phys Med Rehabil. 2007 Sep 1;88(9):1114-1120.

32. Steele KM, Rozumalski A, Schwartz MH. Muscle synergies and complexity of neuromuscular control during gait in cerebral palsy. Dev Med Child Neurol. 2015 Dec;57(12):1176-1182. PMCID: PMC4683117

33. Hicks JL, Delp SL, Schwartz MH. Can biomechanical variables predict improvement in crouch gait? Gait Posture. 2011 Jun;34(2):197-201. PMCID: PMC3130107

34. Rajagopal A, Kidziński Ł, McGlaughlin AS, Hicks JL, Delp SL, Schwartz MH. Estimating the effect size of surgery to improve walking in children with cerebral palsy from retrospective observational clinical data. Sci Rep. 2018 Nov 5;8(1):16344.

35. Shore BJ, Yu X, Desai S, Selber P, Wolfe R, Graham HK. Adductor Surgery to Prevent Hip Displacement in Children with Cerebral Palsy: The Predictive Role of the Gross Motor Function Classification System. JBJS. 2012 Feb 15;94(4):326-334.

36. Chambers H, Lauer A, Kaufman K, Cardelia JM, Sutherland D. Prediction of Outcome After Rectus Femoris Surgery in Cerebral Palsy: The Role of Cocontraction of the Rectus Femoris and Vastus Lateralis. J Pediatr Orthop. 1998 Dec;18(6):703-711. 
medRxiv preprint doi: https://doi.org/10.1101/2022.01.04.21268561; this version posted January 5, 2022. The copyright holder for this preprint (which was not certified by peer review) is the author/funder, who has granted medRxiv a license to display the preprint in perpetuity.

It is made available under a CC-BY-NC-ND 4.0 International license .

37. Galarraga C. OA, Vigneron V, Dorizzi B, Khouri N, Desailly E. Predicting postoperative gait in cerebral palsy. Gait Posture. 2017 Feb 1;52:45-51.

38. Pearl J. Causal inference in statistics: An overview. Stat Surv. Amer. Statist. Assoc., the Bernoulli Soc., the Inst. Math. Statist., and the Statist. Soc. Canada; 2009 Jan;3(none):96-146.

39. Imbens GW, Rubin DB. Causal Inference in Statistics, Social, and Biomedical Sciences. Cambridge University Press; 2015.

40. Pearl J. Causal Diagrams for Empirical Research. Biometrika. [Oxford University Press, Biometrika Trust]; 1995;82(4):669-688.

41. Chipman HA, George EI, McCulloch RE. BART: Bayesian additive regression trees. Ann Appl Stat. Institute of Mathematical Statistics; 2010 Mar;4(1):266-298.

42. Hahn PR, Murray JS, Carvalho CM. Bayesian Regression Tree Models for Causal Inference: Regularization, Confounding, and Heterogeneous Effects (with Discussion). Bayesian Anal. International Society for Bayesian Analysis; 2020 Sep;15(3):965-1056.

43. Hill JL. Bayesian Nonparametric Modeling for Causal Inference. J Comput Graph Stat. Taylor \& Francis; 2011 Jan 1;20(1):217-240.

44. Dorie V, Hill J, Shalit U, Scott M, Cervone D. Automated versus Do-It-Yourself Methods for Causal Inference: Lessons Learned from a Data Analysis Competition. Stat Sci. Institute of Mathematical Statistics; 2019 Feb;34(1):43-68.

45. Williams TC, Bach CC, Matthiesen NB, Henriksen TB, Gagliardi L. Directed acyclic graphs: a tool for causal studies in paediatrics. Pediatr Res. 2018 Oct;84(4):487-493.

46. Verma T, Pearl J. Equivalence and synthesis of causal models. UCLA, Computer Science Department Los Angeles, CA; 1991;

47. Brewer LE, Wright JM, Rice G, Neas L, Teuschler L. Causal inference in cumulative risk assessment: The roles of directed acyclic graphs. Environ Int. 2017 May 1;102:30-41.

48. Shrier I, Platt RW. Reducing bias through directed acyclic graphs. BMC Med Res Methodol. 2008 Oct 30;8(1):70.

49. Textor J, van der Zander B, Gilthorpe MS, Liśkiewicz M, Ellison GT. Robust causal inference using directed acyclic graphs: the R package 'dagitty.' Int J Epidemiol. 2016 Dec 1;45(6):1887-1894.

50. R Core Team. R: A Language and Environment for Statistical Computing [Internet]. Vienna, Austria: R Foundation for Statistical Computing; 2021. Available from: https://www.R-project.org/ 
medRxiv preprint doi: https://doi.org/10.1101/2022.01.04.21268561; this version posted January 5, 2022. The copyright holder for this preprint (which was not certified by peer review) is the author/funder, who has granted medRxiv a license to display the preprint in perpetuity.

It is made available under a CC-BY-NC-ND 4.0 International license.

51. Schwartz MH, Rozumalski A. The Gait Deviation Index: a new comprehensive index of gait pathology. Gait Posture. 2008 Oct;28(3):351-357. PMID: 18565753

52. Shuman BR, Schwartz MH, Steele KM. Electromyography Data Processing Impacts Muscle Synergies during Gait for Unimpaired Children and Children with Cerebral Palsy. Front Comput Neurosci. 2017;11:50. PMCID: PMC5460588

53. Tan YV, Roy J. Bayesian additive regression trees and the General BART model. ArXiv190107504 Stat [Internet]. 2019 Jan 22 [cited 2021 Jul 27]; Available from: http://arxiv.org/abs/1901.07504

54. Buuren S van, Groothuis-Oudshoorn K. mice: Multivariate Imputation by Chained Equations in R. J Stat Softw. 2011;45(3):1-67.

55. Kapelner A, Bleich J. bartMachine: Machine Learning with Bayesian Additive Regression Trees. J Stat Softw. 2016;70(4):1-40.

56. Molnar C, Bischl B, Casalicchio G. iml: An R package for Interpretable Machine Learning. JOSS. Journal of Open Source Software; 2018;3(26):786.

57. Massaad A, Assi A, Skalli W, Ghanem I. Repeatability and validation of Gait Deviation Index in children: Typically developing and cerebral palsy. Gait Posture. 2014 Jan 1;39(1):354-358. 